\title{
A CASE OF HYPERTELORISM.
}

BY

\author{
W. B. DPUMMON1), M.D., F.R.C.P. (Edin.). \\ (Medical Superintendent of Baldovan Institution, by Dundee.)
}

Hypertelorism is the name given to a rare congenital cranio-facial deformity by D. M. Greig( ${ }^{(2)}$ who was the first to differentiate the condition from other deformities of the cranium. The chief characteristic of the condition is an excessive distance between the eyes producing an appearance reminiscent of that of the Fish-Footman in Alice in Wonderland. In a paper published in 1924 he describes two cases and gives a very full description (If the skull of the more advanced case. So far as I know only six cases have been described, but no doubt the small number of the published cases is due to the condition having been undifferentiated from other deformities such as oxycephaly. I have myself seen three cases includin one of Greig's. As the descriptions of the published cases are readily accessible, I shall not summarise the papers that have been published, but shall proceed at once to describe the case which is at present under my care.

Thomas R. Age, 11 years 4 months. Mental age, 51 $\frac{0}{2}$. Intelligence quotient, 51. This boy was admitted to Baldovan Institution on 16th January, 1926. He is the older of two children. His parents are normal physically and mentally, except that his mother is said to have had a goitre for four years. She has not been seen by the writer. Her husband states that the goitre is not very large, but becomes larger when she is agitated; that she is nervous, has a quick pulse, and often complains of ralpitation or of "her heart stopping"; that there is no undue prominence of her eyes. During her pregnancy she was in good health, but her legs became much swollen before the child's birth, so that she often had to lie down in the afternoons. The child's birth was nornial, and he was nursed at the breast, but he was a delicate baby and did not sit up till he was 2 years of age nor walk till he was 4 years old. He wass operated on for rupture at the age of 2 , but the operation was unsuccessful, and was: repeated last June with success. He wears no truss.

$\mathrm{He}$ is a fairly healthy-looking child, but is very small for his age, his height being $3 \mathrm{ft} .9 \frac{1}{4} \mathrm{ins}$, and his weight 3 st. $4 \mathrm{lbs}$. This is approximately eight inches less than the average height for his age, and $26 \mathrm{lbs}$. less than the normal weight. He appears to have a large head. As a matter of fact the circumference of his head is slight!y below the average for a boy of his age, but is decidedly above the average for a boy of his height-say an average boy $6 \frac{1}{2}$ years of age. The circumference of his head is $21 \frac{1}{2}$ inches and is the same as that of his chest; whereas, at his age, the chest meas!rement should be at least two inches greater than that of the head. The forehead is somewhat square, and the frontal eminences prominent, there being a suggestion of a vertical groove or hollow down the centre of the forehead reappearing at the tip of the nose. The bridge of the nose is broad and flat.

The most remarkable feature, however, is the abno:mal distance between the eyes. The distance between the pupils, when the child is looking directly forward, is $2 \frac{3}{4}$ inches as compared with $2 \frac{1}{4}$ inches in an adult. The distance between the inner canthi is $2 \frac{1}{2}$ inches. The eyes are very slightly prominent, and although the child can look directly forward there is usually a slight external strabismus of the right eye. Convergence on near objects is imperfect, but is fairly good if his intẹest is excitẹd, 
In Greig's first case the skull was brachy-cephalic (index 82) with " a low forehead, a pronounced vertex rising more posterior to the bregma than usual, and a flat occiput." These features are not observed in the present case, where the cephalic index is 79.9 , the forehead is fairly high, and the antero-posterior configuration of the skull is normal.

The mouth is small. The palate is ligh and narrow. The tongue is large and slightly fissured as in tongue-sucking children. The lower jaw is prognathous and the lower incisors bite in front of the stumps of the upper incisors. He has had 28 teeth, but four premolars are absent, and four tecth, including the two upper central incisors, are mere stumps.

The hands are of fair size. The skin is thick and soft and the hand reminds one of that of a Mongol, but the fissures on the palms do not have the arrangement which has lately been described as characteristic of Mongols. The feet, also, are soft and the forepart of the foot is remarkably broad.

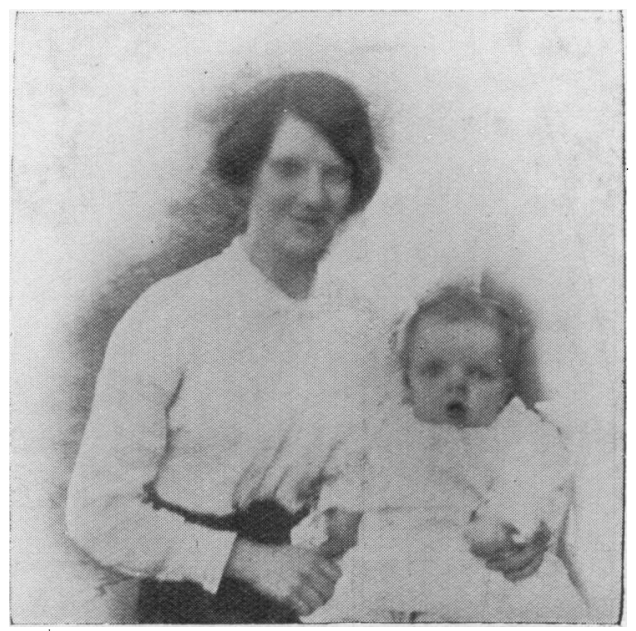

Fig. 1 .

Patient at the age of 11 months.

There is no acro-cyanosis, and the circulatory system is apparently normal, but when the dentist was extracting a stump under a local anæsthetic, the patient's face became so intensely cyanosed that the operator was afraid to extract any more. The gum bled very copiously and the blood coagulated quickly.

The child speaks well and takes an intelligent interest in his surroundings. Probably he is a little more intelligent than his low I.Q. seems to indicate, his mental deficiency being associated with a certain amount of mental retardation. The Binet tests quite justifiably presupposes school attendance from the age of 5 or 6 years, and consequently a child. who has had little or no school attendance is liable to be given a rating which does not do full justice to his real mental capacity. The reason the child has not attended school is that the father did not wish to send him owing to his peculiar appearance. The school medical officer saw him at home and apparently no suggestion was made that he should be sent to a special school or institution until his parents removed to town.

The illustrations show the appearance of the child at different ages, and the contours of the skull as traced by means of a cyrtometer, 
As to the nature of the condition, Greig regards all the deformities of the skull results of the abnormal shape of the sphenoid bone. The fons et origo: mali he states as follows: "An interference with development, going back early in embryonic life, present certainly in the chondro-cranium and perhaps in the mesoblastic tissue in

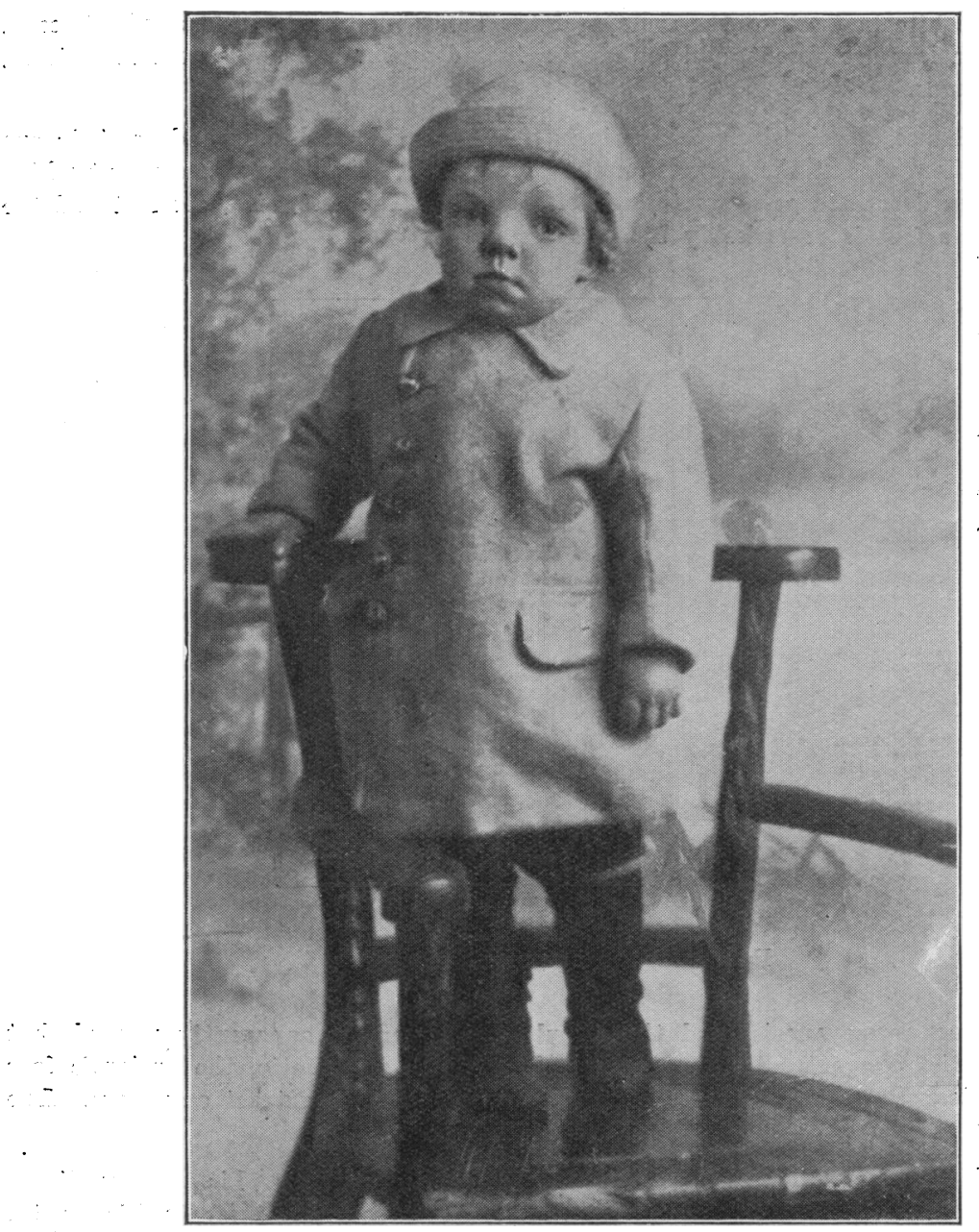

r'ig. 2.

Patient at the age of about 4 years.

which the chondro-cranium is laid down, a result of that hereditary want of balance in development, which in families marked by Nature for extinction, brings forth the physically and mentally maimed and defective individuals whom we stigmatise as 'Degenerates.' '

There does not, however, appear to be anything in the family history of the present case, nor in that of most of the other published cases, to support 
the view that the condition is due to a bad heredity. The condition is congenital, and results from causes acting at an early period of embryonic life, but there are good grounds for believing that monstrosities are liable to be produced by intra-uterine environmental causes acting upon the embryo. In short, the condition may, be analogous to the teratological or fincy forms of fish which Tornier, and Stockard, have proved experimentally to result from the embryos being allowed to develop in insanitary conditions.

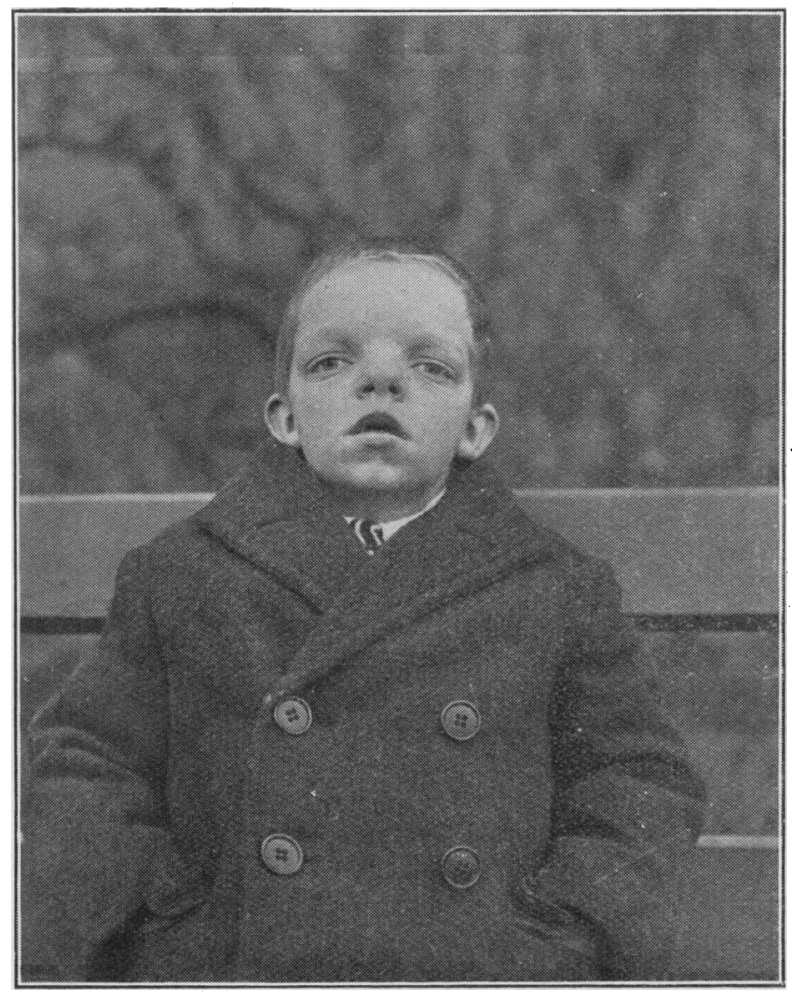

Fig. 3.

Patient at thes age of $11 \frac{1}{3}$ years. $\because$ :

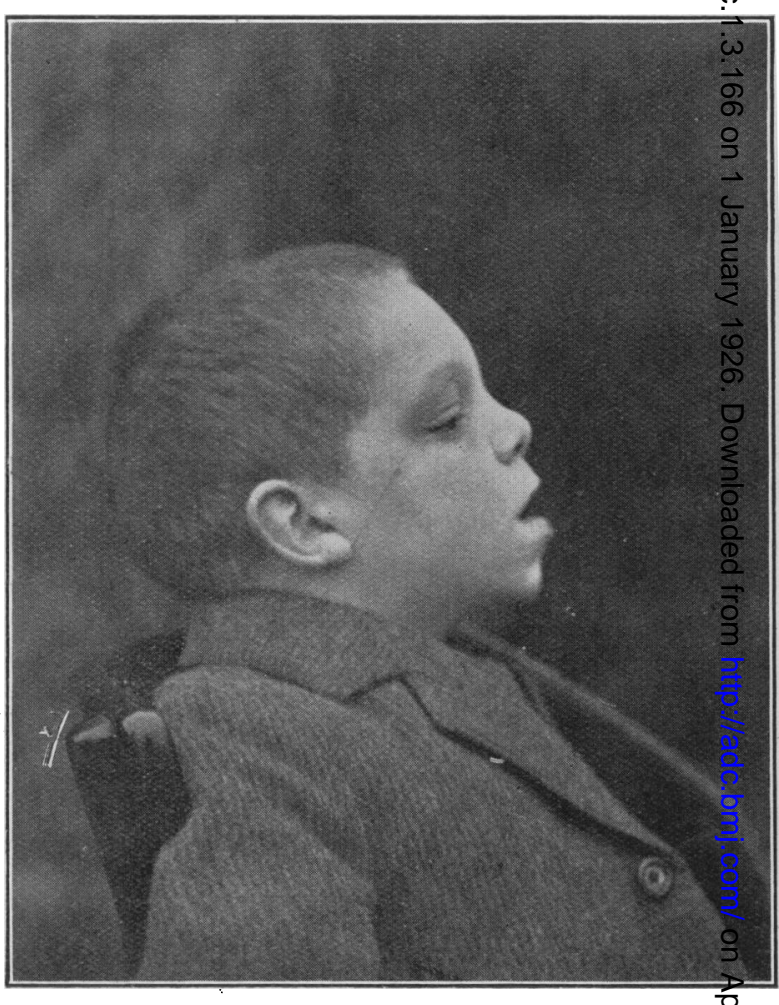

Fig. 4.

Patient at the age of $11 \frac{1}{3}$ years (profile).

For example, there is the variety of gold fish known as the "telescope fish" in which the eyes protrude from the sides of the head and the tail is doubled. According to Tornier, this is a mutation which results from weakening of the vigour of the germ cell by the abstraction of oxygen from the water during the first few days of its life. If hypertelorism may be explained as the result of some failure of nutrition and deficient oxygenation in early life, the other structural abnormalities present may be direct results of the same cause. It seems just as likely that the defective development of the hrain indicated by the mental deficiency is to be accounted for in this way as that it results from the mechanical interference with its growth suggested by Greig. 


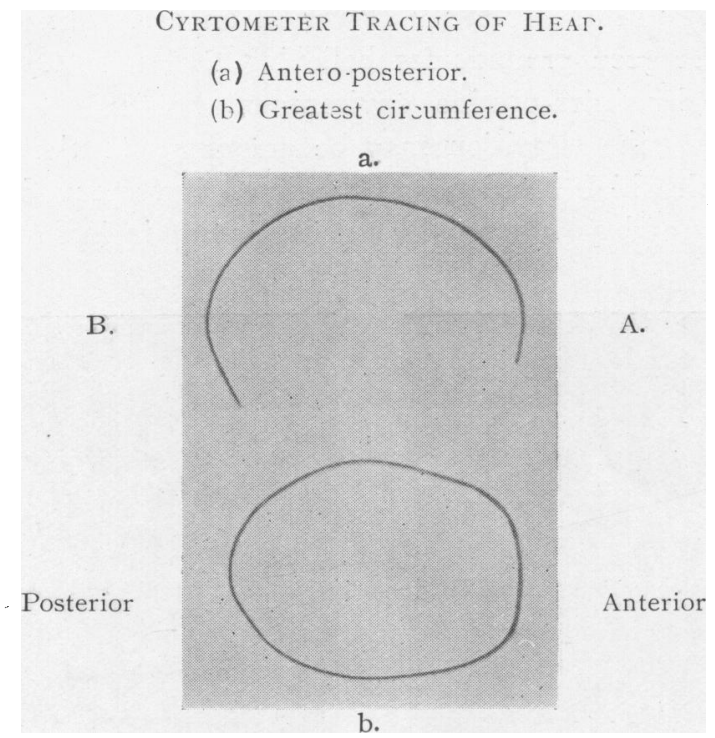

Fig. 5 .

RF.FERENCES.

1. Cockayne, E. A. : British Journal of Children's Diseases," 1925, xxii., 265.

2. Greig, D. M. : Edin. Med. Journ., 1924, N.S. xxxi., 560.

3. Hutchison, R. : Proc. Roy. Soc. Med., 1909-1910, iii., Sect. Study Dis. Child., 125

4. Muir, D. C. : British Journal of Children's Diseases, 1925, xxii., 102. 